\title{
Is Latent Syphilis New Normal among Clinical Presentations of Syphilis? Study from a Tertiary Care Institute
}

\author{
Padhiyar JK, Patel NH, Buch J, Chhibber A \\ Department of Dermatology, GCS Medical College Hospital \& Research Institute, Ahmedabad, Gujarat, India.
}

\begin{abstract}
Introduction: Clinical presentation of syphilis varies widely according to stage of syphilis. Latent syphilis pose special challenge for diagnosis as patient is usually asymptomatic and still infectious.

Material and Methods: Retrospective analysis of Rapid plasma regain (RPR) positive patients over two years duration from tertiary care institute was carried out.

Results: A total of 32 RPR positive patients were analyzed. Eleven (34.37\%) patients had clinical features suggestive of Syphilis, rest 21 (65.63\%) patients were found to be positive by RPR without any clinical signs and symptoms. Seven patients $(21.8 \%)$ had genital ulcerative diseases at the time of presentation.

Conclusion: Our study reports rise in incidence of latent syphilis.

Key words: Genitalia; Sexually Transmitted Diseases; Syphilis, latent
\end{abstract}

\section{Introduction}

Ceroprevalence of syphilis is not exactly known because of stigma associated with it and lack of effective screening for various sexually transmitted diseases (STDs) in developing countries. Studies are also revealing contradictory findings on the seroprevalence of syphilis- some studies have shown decreasing prevalence while other showed resurgence of syphilis has been reported by others. ${ }^{1,2,3}$

Clinical presentation of the disease varies widely according to the stage of syphilis. In the latent phase of the disease patient is usually asymptomatic but still infective though infectivity reduces after early latent syphilis, thus being culprit in spreading disease in contacts if remain untreated. A retrospective clinicoepidemiological analysis was carried out to find prevalence and changing clinical pattern of syphilis.

\section{Material and Methods}

Retrospective analysis was carried out on clinical and epidemiological data obtained from the department

\footnotetext{
Address of Correspondence:

Dr. Nayankumar Harshadkumar Patel

Associate Professor

Department of Dermatology

GCS Medical College Hospital \& Research Institute,

Ahmedabad, Gujarat, India

E-mail: patelnayan78.np@gmail.com
}

of Dermatology, Venereology and Leprology of a tertiary care institute. Patients with seropositivity for RPR (rapid plasma reagin) tests over the period of two years (from April 2016 to March 2018) were included for the analysis. These patients were from various groups like antenatal cases, attendees of STD clinic, blood donors or HIV positive patients. Other records of these patients like detailed clinical history, exposure history, TPHA (treponema pallidum hemagglutination), serological tests for HIV (human immunodeficiency virus), CSF-VDRL (cerebrospinal fluid-Venereal Disease Research Laboratory) test, Dark ground illumination (DGI) microscopy and Tzanck smear analysis were evaluated in detail.

\footnotetext{
Submitted: $25^{\text {th }}$ July 2018

Accepted: $15^{\text {th }}$ November 2018

Published: $31^{\text {st }}$ March 2019
}

How to cite this article

Padhiyar JK, Patel NH, Buch J, Chhibber A. Is latent syphilis new normal among clinical presentations of syphilis ? Study from a tertiary care institute. Nepal Journal of Dermatology, Venereology and Leprology. 2019;17(1):27-31. doi: http:// dx.doi.org/10.3126/njdvl.v17i1.23247

\section{(c) (i)}

Licensed under CC BY 4.0 International License which permits use, distribution and reproduction in any medium, provided the original work is properly cited. 


\section{Results}

A total of 7750 patients who attended STD clinic, Antenatal clinic were screened for positive RPR reactivity. Results of TPHA and DGI studies for all patients who were positive for RPR were also analyzed. Thirty two patients with RPR positivity were included for the study. TPHA was positive in all but one case of primary syphilis which was confirmed by dark ground illumination microscopy. Out of total 2496 STD clinic attendees including blood donors and HIV positive patients, $28(1.12 \%)$ were found to be positive by RPR. Four (0.08\%) out of total 5254 antenatal clinic attendees were found to be positive by RPR. One antenatal patient had history of abortion at seventh month of pregnancy.

Male: Female ratio was 1.9:1. Mean age of the patients was $28.23 \pm 10.73$ years with youngest patient being 5 years of age and oldest patient being 55 years of age. Four (12.5\%) patients were below the age of 18 years. Three $(9.37 \%)$ patients had history of child sexual abuse and one of these patients also had history of forced drug abuse. Homosexual behavior was noted in two (6.25\%) patients.

Out of 32 patients, only 11 (34.37\%) patients had clinical features suggestive of Syphilis, rest 21 (65.63\%) were found to be positive by RPR without any clinical signs and symptoms. History of ulcerative genital lesions was given by only four patients. Out of these four patients, two had latent syphilis whereas two had secondary syphilis at the time of presentation. Table 1 shows the screening profile of all the patients.

Table 1: Screening profile of patients ( $n=32)$.

\begin{tabular}{|l|c|}
\hline Primary syphilis & 1 \\
\hline Secondary syphilis & 9 \\
\hline $\begin{array}{l}\text { Mixed STD (Herpes progenitalis + Syphilitic } \\
\text { chancre with unilateral bubo) }\end{array}$ & 1 \\
\hline Herpes Progenitalis & 5 \\
\hline Genital molluscum contagiosum & 1 \\
\hline Vulvo vaginal candidiasis & 2 \\
\hline Urethral discharge (gonorrhea) & 1 \\
\hline Genital scabies & 1 \\
\hline Partners of RPR positive patients & 4 \\
\hline Antenatal patients & 4 \\
\hline HIV patients & 2 \\
\hline Blood donors & 1 \\
\hline Total & 32 \\
\hline
\end{tabular}

Seven out of 32 patients who were tested positive for RPR had genital ulcer as presenting symptom. Of these seven patients one patient was clinically diagnosed as primary syphilis and confirmed by DGI (Tzancknegative). One more patient had clinical diagnosis of Herpes progenitalis but found to be positive for Treponema Pallidum on DGI examination with characteristic syphilitic lymph node enlargement(Figure 1). Rest 5 patients had clinical diagnosis of Herpes Progenitalis confirmed on Tzanck smear examination and found to be RPR positive on investigation.

Clinical examinations of 11 patients who had signs and symptoms suggestive of syphilis showed clinical spectrum as in table-2. Figure 1, 2 and 3 illustrates different types of clinical presentations of primary and secondary stage of the disease.

Table 2: Spectrum of clinical features in 11 patients.

\begin{tabular}{|l|c|}
\hline Type of lesion & No. of Patients \\
\hline $\begin{array}{l}\text { Syphilides over palms and } \\
\text { soles }\end{array}$ & 4 \\
\hline Maculo-papular eruptions & 3 \\
\hline $\begin{array}{l}\text { Papulosquamous psoriasiform } \\
\text { lesions }\end{array}$ & 2 \\
\hline $\begin{array}{l}\text { Buschke olendroff sign } \\
\text { positivity }\end{array}$ & 4 \\
\hline Condyloma lata & 1 \\
\hline Annular lesion over face & 2 \\
\hline Lichenoid itchy eruptions & 5 \\
\hline $\begin{array}{l}\text { Non tender Inguinal lymph } \\
\text { nodes enlargement }\end{array}$ & 2 \\
\hline $\begin{array}{l}\text { Epitrochlear lymph node } \\
\text { enlargement }\end{array}$ & 2 \\
\hline Primary chancre & $\begin{array}{l}\text { 1 (CSF-VDRL } \\
\text { negative, but intra } \\
\text { cranial tension/ } \\
\text { Pressure was raised }\end{array}$ \\
\hline $\begin{array}{l}\text { Systemic symptoms like } \\
\text { headache, vertigo, blurring of } \\
\text { vision }\end{array}$ & \\
\hline
\end{tabular}

Patients with positivity of serological tests without clinically evident disease were thoroughly evaluated for signs and symptoms of cardiovascular and neurological involvement. Evaluation did not suggest any abnormality, so CSF-VDRL was not performed. These patients were considered to have latent syphilis. One of the patients of secondary syphilis had associated systemic symptoms like headache, vertigo and blurring of vision but CSF-VDRL test was negative though intracranial pressure was raised.

All patients were treated according to standard treatment of care for the syphilis. 


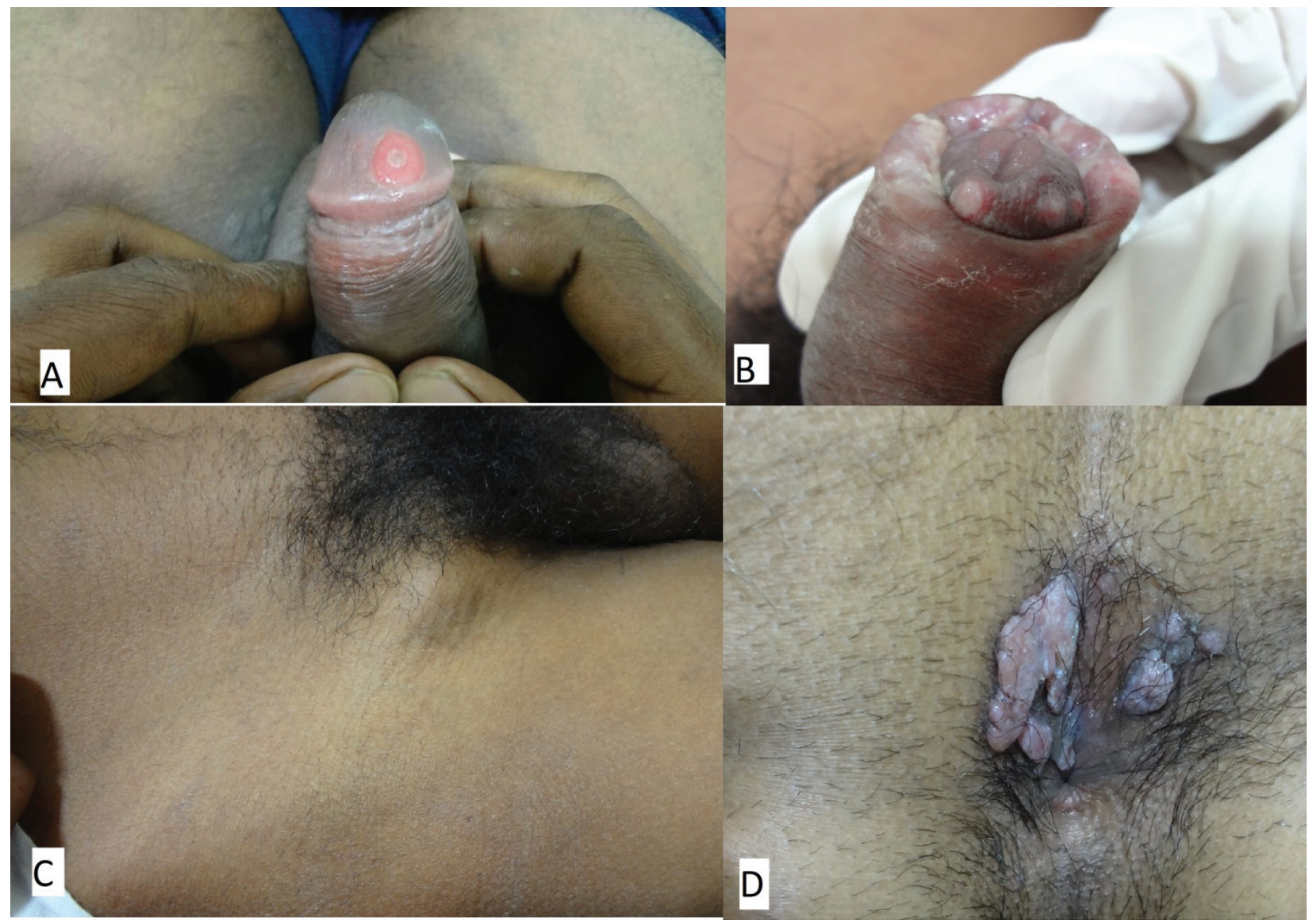

Figure-1: (A) primary chancre (B) co-infection of primary syphilis with herpes progenitalis (C) Inguinal syphilitic bubo in same patient as in -b (D) condylomata lata as sole manifestation in a child with sexual abuse.

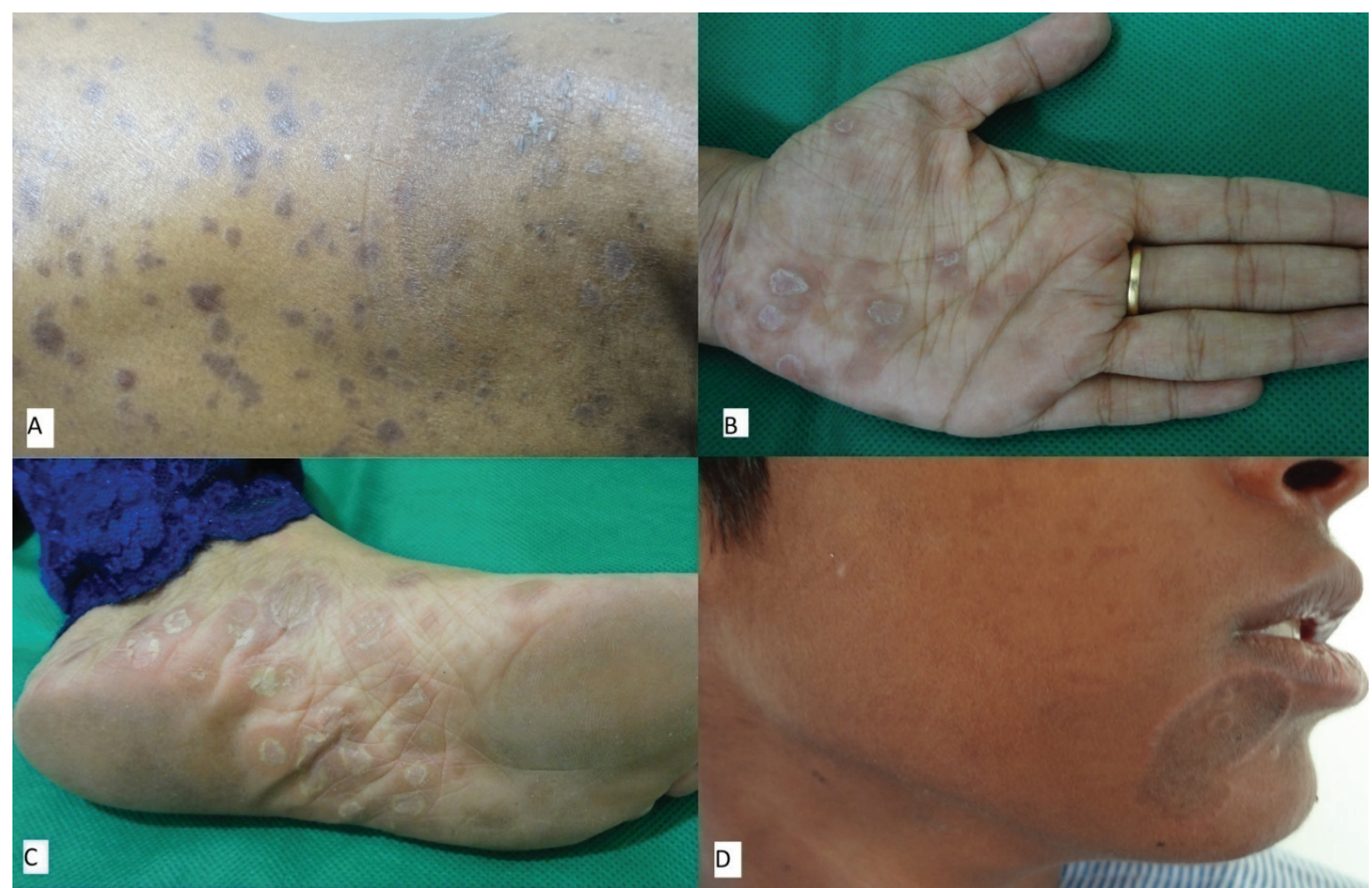

Figure-2: (A) lichenoid itchy papules in secondary stage (B \& C) palmar and plantar syphilides respectively (D) annular lesion on face in secondary stage. 


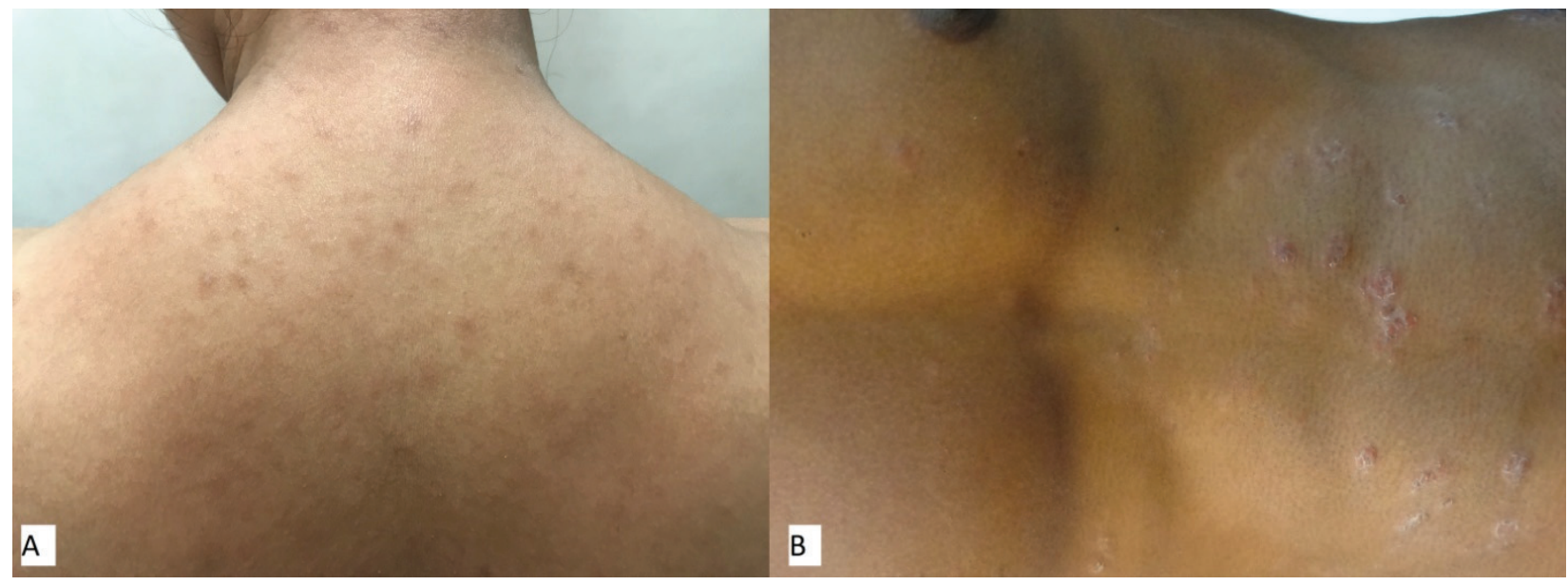

Figure 3: (A) maculo-papular rash in secondary stage (B) psoriasiform lesions in secondary stage.

\section{Discussion}

Though viral STIs dominates in epidemiological studies, syphilis has maintained constant prevalence, in fact many studies have reported resurgence of syphilis worldwide. ${ }^{4,5,6}$

Contrary to study by Jain A et al, our study observed commonest presentation being latent stage of the disease in $65.63 \%$, followed by secondary syphilis (28.13\%) and primary syphilis (6.25\%). ${ }^{7}$ While other studies have reported rise in the secondary stage of the disease ${ }^{2,8}$. This contradictory finding in current study may be due to asymptomatic nature of the lesions, lack of accurate diagnosis at the time of disease manifestation or inadequate treatment in primary and secondary stage of the disease.

Presentation of secondary stage of the disease is also changing with fewer evident clinical lesions and signs as observed in our study. High degree of suspicion is required in changing era of clinical presentation. Buschke olendroff sign and enlargement of epitrochlear lymphnode which are considered classic presentation of the disease was present only in two (6.25\%) patients. Palmoplantar syphilides were also observed in only four (12.5\%) patients. Oral lesions were not observed in any of our patients.

As reported by Khan S et al, current study also found low seroprevalence of syphilis (0.08\%, 4 out of 5254) in antenatal patients. ${ }^{9}$ However, as syphilis can be an etiology of adverse outcome of pregnancy in majority of cases, screening of all antenatal patients for syphilis must be done. In our study also, one patient had a past history of abortion in last trimester of previous pregnancy.
Patel HK et al reported $3.46 \%$ patients were of less than 15 years of age, while in our study we found almost double (6.25\%) number of patients being less than 15 years of age. ${ }^{10}$ There was also history of sexual abuse in these patients along with one other patient in age group of 16-18 years. Condyloma lata was the sole manifestation in one of these male children.

Out of total 92 HIV positive patients during the study period, two $(2.22 \%)$ patients were found to be RPR and TPHA reactive without any signs and symptoms in current study. Patel HK et al and Khan $\mathrm{S}$ et al found much higher incidence of co-infection rates, $6.25 \%$ and $6.5 \%$ respectively. Sethi $S$ et al observed secondary or latent syphilis was most common presentation in patients of co-infection with HIV. ${ }^{11}$ Though our study had less number of patients compared to them, both patients with co-infection had latent syphilis.

Our study being a retrospective analysis of patients ascending to our hospital only, it might not reflect the community burden of the disease. Being retrospective analysis multiple consultants were involved in clinical diagnosis so observational bias cannot be ruled out.

\section{Conclusion}

Our study report rise in incidence of latent syphilis, though this result has to be interpreted with caution and further study on larger population is needed. High risk population needs to be regularly screened for syphilis in latent stage. With changing era of subtle clinical presentation, high index of suspicion and thorough examination is also required not to miss the diagnosis in primary and secondary stage.

Financial support: None

Conflict of interest to disclosure: None declared. 


\section{References}

1. Jain VK, Dayal S, Aggarwal K, Jain S. Changing trends of sexually transmitted diseases at Rohtak. Indian J Sex Trans Dis. 2008;29:23-5. https://doi. org/10.4103/0253-7184.42710

2. Ray K, Bala M, Gupta SM, Khunger N, Puri P, Muralidhar S, et al. Changing trends in sexually transmitted disease in a regional STD centre in north India. Indian J Med Res. 2006;124:559-68.

3. Schumacher CM, Ellen J, Rompalo AM. Changes in demographics and risk behaviors of person with early syphilis depending on epidemic phase. Sex Transm Dis. 2008;35:190-6. https://doi. org/10.1097/OLQ.0b013e31815a88b0

4. CDC. Sexually Transmitted Disease Surveillance 2012. Atlanta: U.S. Department of Health and Human Services; 2013. Available from: https:// www.cdc.gov/std/stats/ [Accessed on 10 $10^{\text {th }}$ July 2018].

5. PHE. Recent Epidemiology of Infectious Syphilis and Congenital Syphilis Health Protection Report. 2013:7. Available from: https://assets.publishing. service.gov.uk/government/uploads/system/ uploads/attachment_data/file/336760/hpr4413_ sphls.pdf [Accessed 10 July 2018]
6. Hook EW. Syphilis. The Lancet. 2017;389:1550-57. https://doi.org/10.1016/S0140-6736(16)324114.

7. Jain A, Mendiratta V, Chander R. Current status of acquired syphilis: A hospital based 5- year study. Indian J Sex Trans Dis. 2012;33(1):32-34. https:// doi.org/10.4103/0253-7184.93814

8. Kar HH. Incidence of secondary Syphilis on a rise and need for a separate flow chart for its syndromic management. Indian J Sex Trans Dis. 2004;25:22-5.

9. Khan S, Menezes GA, Dhodapkar R, Harish BN. Seroprevalence of syphilis in patients attending a tertiary care hospital in Southern India. Asian Pac J Trop Biomed. 2014;4(12):995-997. https://doi. org/10.12980/APJTB.4.201414B413

10. Patel HK, Patel PH, Nerurkar AB. Seroprevalence of Syphilis in Patient Attending Tertiary Care Hospital, Valsad, India. Int J Curr Microbiol App Sci. 2017;6(6):2702-6. https://doi.org/10.20546/ ijcmas.2017.606.321

11. Sethi S, Mewara A, Hallur V, Prasad A, Sharma $\mathrm{K}$, Raj A. Rising trends of syphilis in a tertiary care center in North India. Indian J Sex Trans Dis. 2015;36(2):140-143. https://doi. org/10.4103/0253-7184.167137 